\title{
The Draft Digital Markets Act: A Legal and Institutional Analysis
}

\author{
Pablo lbáñez Colomo*
}

\section{Introduction}

The proposal for a Digital Markets Act signals a new approach to the regulation of Big Tech in the EU and beyond. ${ }^{1}$ The legislative machine has been set in motion following a change in the attitude of authorities and stakeholders vis-à-vis the growing and transformative role of online platforms in the economy. It has been argued-including in a number of reports for public authorities ${ }^{2}$ - that competition law, in its current incarnation, would be unable to address the challenges raised by Big Tech. According to this view, it would not be sufficiently effective to respond to the actual or potential effects resulting from the power wielded by these firms. Several alleged flaws have been identified, including its procedural guarantees and case-specific nature (which delays the adoption of decisions), the substantive standards (which would place undue demands on authorities and claimants when establishing an infringement) or the remedies (which would not go far enough to restore the competitive process).

The various recipes that have been proposed to regulate Big Tech share the main ingredients. To begin with, they tend to be based on the premise that digital markets display a number of features that demand ad hoc rules. ${ }^{3}$ Second, the proposals advanced seek to dispense from the

* London School of Economics and College of Europe. E-mail: P.IbanezColomo@lse.ac.uk. In accordance with the ASCOLA declaration of ethics, I am happy to clarify that I have nothing to disclose.

1 Proposal for a Regulation of the European Parliament and of the Council on contestable and fair markets in the digital sector (Digital Markets Act) $\operatorname{COM}(2020) 842$ final (hereinafter, the 'Draft DMA').

2 See in particular Jacques Crémer, Yves-Alexandre de Montjoye and Heike Schweitzer, Competition Policy for the Digital Era, available at http://ec.eu ropa.eu/competition/publications (hereinafter, the 'Special Advisers' Report'); Jason Furman and others, Unlocking digital competition: Report of the Digital Competition Expert Panel (March 2019); Fiona Scott Morton and others, 'Committee for the Study of Digital Platforms: Market Structure and Antitrust Subcommittee Report' George J. Stigler Center for the Study of the Economy and the State (1 July 2019); and A New Competition Framework for the Digital Economy: Report by the Commission 'Competition Law 4.0' (September 2019).

3 The Special Advisers' Report (p. 2), in particular, focuses on three features: (i) extreme returns to scale; (ii) network externalities; and (iii) the role of data.

(C) The Author(s) 2021. Published by Oxford University Press.

This is an Open Access article distributed under the terms of the Creative Commons Attribution License (http://creativecommons.org/licenses/by/4.0/), which permits unrestricted reuse, distribution, and reproduction in any medium, provided the original work is properly cited.

\section{Key Points}

- The Draft DMA sets up a new regulatory regime that would relieve the European Commission from the legal and economic constraints deriving from competition law.

- Under the legislative proposal, undertakings categorised as gatekeepers would bear the burden of complying with the obligations.

- The combination of these two factors would afford the European Commission substantial leeway to restructure digital ecosystems and reallocate rents across the value chain.

- While it is not obvious to see whether administrative action would be subject to meaningful constraints, these are required to ensure effective judicial protection.

need to establish, on a case-by-case basis, the anticompetitive object and/or effect of a practice. More generally, the ideas floated so far seek to minimise the need for the sort of context-specific fact-finding exercises that characterise competition law systems. The proposed moves seek to ensure that intervention is fast and, if necessary, preemptive. Third, it is typically argued that the substantive standards of competition law should be relaxed so as to make intervention easier. Finally, it is not unusual to hear that remedies should be far-reaching and, where needed, introduce a restorative element reinjecting competition in the relevant markets.

The Draft Digital Markets Act (hereinafter, the 'Draft DMA') shares the abovementioned ingredients. Crucially, the instrument amounts to more than a simple tweak of competition law provisions. Instead of retaining the logic, structure and approach of Articles 101 and 102 TFEU, the Draft DMA introduces an ad hoc regulatory regime. It departs from competition law in two key respects. First, the proposed system embraces a different set of objectives 
and is therefore said not to be concerned with or, constrained by, the protection of undistorted competition. ${ }^{4}$ Second, it dispenses from the need to show, on a caseby-case basis, the anticompetitive object and/or effect of a practice. ${ }^{5}$ In fact, the impact of a practice and/or whether it can be justified on efficiency grounds are irrelevant considerations. ${ }^{6}$ Instead, the Draft DMA identifies a series of obligations to be fulfilled by 'gatekeepers' in relation to their 'core platform services.' Such duties relate, inter alia, to self-preferencing ${ }^{8}$ or 'most favoured-nation' clauses. ${ }^{9}$ In this sense, the Draft DMA entails a reversal of the burden of intervention: it is not for the authority to establish an infringement and impose a duty, but rather for firms to define how they intend to comply with the obligations enshrined in the proposal.

Because it is an instrument that provides, ex ante, for a set of regulatory duties, the Draft DMA is more akin to the EU Regulatory Framework for Electronic Communications (the 'EU telecoms regime'). ${ }^{10}$ Just like the Draft DMA, the said regime is designed to adapt to technological and economic change and provides for a mechanism to identify firms subject to regulatory obligations. There are, however, important differences between the two. The EU telecoms regime, far from avoiding competition law concepts, is built around them. What is more, the point of the framework is to create the circumstances in which ex ante intervention becomes unnecessary and telecommunications activities are subject to competition law alone. In this sense, it constrains the behaviour of regulatory authorities in that it defines with precision when action is justified and when it is to be rolled back. Insofar as it does, it places the burden of intervention on the agency, not the firm. The Draft DMA, by contrast, does not share the same aspiration and anticipates an overlap with competition law. In addition, it is not clear about when and why regulatory obligations are to be removed.

The purpose of this paper is, first, to explain the differences between the Draft DMA and both competition

4 See in this sense the Preamble to the Draft DMA, Recital 10.

5 Ibid., Recital 9.

6 Ibid., in particular Recital 23: '[a]ny justification on economic grounds seeking to demonstrate efficiencies deriving from a specific type of behaviour by the provider of core platform services should be discarded, as it is not relevant to the designation as a gatekeeper'.

7 Articles 5 and 6.

8 Ibid. On self-preferencing, see Pablo Ibáñez Colomo, 'Self-Preferencing: Yet Another Epithet in Need of Limiting Principles' (2020) 43 World Competition 417.

9 Ibid. On most favoured-nation clauses, see Pinar Akman and D Daniel Sokol, 'Online RPM and MFN Under Antitrust Law and Economics' (2017) 50 Review of Industrial Organization 133.

10 See in particular Directive (EU) 2018/1972 of the European Parliament and the Council of 11 December 2018 establishing the European Electronic Communications Code OJ (2018) L 321/36. law and the EU telecoms regime. In line with what has already been outlined, the differences are substantial. As a result of these points of divergence, the European Commission (hereinafter, the 'Commission') would not be subject to the legal, economic and institutional constraints that derive from the experience acquired over decades of enforcement. Because it is a regime defined by a different, autonomous, set of objectives, the Draft DMA provides the Commission with a blank slate on which to define the scope of the regime (namely, what firms qualify as gatekeepers) and the obligations to which providers of core platform services will be subject.

Second, the paper discusses the consequences of the departure from the logic and approach shared by competition law and the EU telecoms regime. Because the proposal is crafted to grant substantial leeway to restructure digital markets and re-allocate rents, it is not immediately apparent whether policy-making will be subject to effective legal, economic and institutional constraints in the way competition law and the EU telecoms regime are. If such constraints eventually emerge, it is not clear where they would originate. For instance, it is not obvious to see how gatekeepers would be in a position to meaningfully challenge - and if so on what grounds-any Commission decisions implementing the Draft DMA. Circumventing the limits that would logically derive from competition law means any constraints would have to develop ex novo.

The remainder of this paper is organised as follows. First, it provides an overview of the operation and main provisions of the Draft DMA. Second, it compares the logic and approach of competition law and that of the proposed regime. The exercise is repeated, third, by contrasting the latter with the EU telecoms regime. It appears that the Draft DMA has defined a new set of legal concepts that have not yet been fleshed out. Finally, the paper discusses the consequences of departing from the objectives and legal concepts that are shared by competition law and the EU telecoms regime. In line with what has been suggested above, the fundamental shift is the substantial leeway awarded to the Commission, which has implications for both judicial review and stakeholders' behaviour and incentives.

\section{An overview of the Draft DMA}

\section{A. Scope and objectives}

The declared ambition of the Draft DMA is to address the perceived negative consequences of the rise of the socalled gatekeepers in the digital economy. In particular, it seeks to achieve 'fair economic outcomes' in the 
industry. ${ }^{11}$ The threat to such outcomes is understood to come, according to the proposal, from the economic features of digital markets. Core platform service providers are deemed able to exploit the said features to their advantage. These are market characteristics that have been extensively explored in recent years and include, in particular, extreme returns to scale, network effects and data-related competitive advantages. ${ }^{12}$ The Draft DMA appears to embrace two objectives: one is to ensure that the digital markets in which gatekeepers operate are and remain contestable. ${ }^{13} \mathrm{~A}$ second objective is the promotion of fairness within these markets. ${ }^{14}$

Against this background, the proposed regime expresses a concern with three separate phenomena (not always expressly distinguished from one another in the draft). First, the strengthening and/or the entrenchment of market power in core platform segments. Given their nature, competition may be difficult to introduce or maintain in these markets. Thus, allowing for entry that would otherwise not have been possible or sustainable is likely to demand the restructuring of incumbents' activities. Second, the Draft DMA seeks to address the potential leveraging of market power from the core platform segment to adjacent activities. Suffice it to think of the relationship between online retailers and marketplaces, or between application developers and application stores. Finally, the regime responds to a concern with the exploitation of market power by core platform providers vis-à-vis customers and suppliers.

The scope of the Draft DMA is defined along two dimensions. First, the nature of the online services offered. The proposal, in this regard, crafts a new legal category, that of 'core platform services'. These are defined in Article 2 of the Draft DMA and comprise, inter alia, search engines, online intermediation services (including application stores), social networking sites, operating systems and cloud computing services. ${ }^{15}$ This

11 Recital 5 of the Draft DMA.

12 See above, $\mathrm{n} 3$. See also Recital 3 of the Draft DMA: '[ . . . ] Contestability is particularly reduced due to the existence of very high barriers to entry or exit, including high investment costs, which cannot, or not easily, be recuperated in case of exit, and absence of (or reduced access to) some key inputs in the digital economy, such as data. As a result, the likelihood increases that the underlying markets do not function well-or will soon fail to function well'.

13 See for instance Recitals 6 and 8.

14 Recitals 4 and 5.

15 Any subsequent references to an article that does not specify the legal instrument must be understood as referring to the Draft DMA. The 'core platform services' identified in Article 2(2) are the following: ' . .. ] (a) online intermediation services; (b) online search engines; (c) online social networking services; (d) video-sharing platform services; (e) number-independent interpersonal communication services; (f) operating systems; (g) cloud computing services; (h) advertising services, including any advertising networks, advertising exchanges and any other advertising list could be expanded following a market investigation conducted by the Commission under Article $17 .{ }^{16}$ The second dimension revolves around the identification of a provider as a 'gatekeeper'. The point of this second dimension is to identify the core platform services that have a particularly important status, which is evaluated in light of three cumulative criteria: (i) their 'significant impact on the internal market'; (ii) the status of the service as 'an important gateway for business users to reach end users'; and (iii) the fact that the provider 'enjoys an entrenched and durable position in its operations or it is foreseeable that it will enjoy such a position in the near future. ${ }^{17}$

The question of whether the provider of a core platform services fulfils the three-criteria test and therefore qualifies as a gatekeeper is ascertained in light of two separate mechanisms. The default mechanism relies on a turnover (or capitalisation) threshold and a user threshold. In this sense, it is not fundamentally different from the approach followed under Regulation 139/2004 to identify concentrations with an EU dimension. ${ }^{18}$ Thus, each of the three criteria is associated with a particular threshold. ${ }^{19}$ Where every one of the thresholds is met by a provider, it is presumed to be a gatekeeper. The Draft DMA allows providers to rebut the presumption by advancing 'sufficiently substantiated arguments' showing that, in spite of

intermediation services, provided by a provider of any of the core platform services listed in points (a) to (g) [ ... ]'.

16 In accordance with Article 17: 'The Commission may conduct a market investigation with the purpose of examining whether one or more services within the digital sector should be added to the list of core platform services or to detect types of practices that may limit the contestability of core platform services or may be unfair and which are not effectively addressed by this Regulation. It shall issue a public report at the latest within 24 months from the opening of the market investigation. Where appropriate, that report shall: (a)be accompanied by a proposal to amend this Regulation in order to include additional services within the digital sector in the list of core platform services laid down in point 2 of Article 2 $[\ldots]$.

17 Article 3(1).

18 See in this sense Article 1 of Council Regulation (EC) No 139/2004 of 20 January 2004 on the control of concentrations between undertakings [2004] OJ L24/1.

19 See in this sense Article 3(2): 'A provider of core platform services shall be presumed to satisfy:(a) the requirement in paragraph 1 point (a) where the undertaking to which it belongs achieves an annual EEA turnover equal to or above EUR 6.5 billion in the last three financial years, or where the average market capitalisation or the equivalent fair market value of the undertaking to which it belongs amounted to at least EUR 65 billion in the last financial year, and it provides a core platform service in at least three Member States; (b) the requirement in paragraph 1 point (b) where it provides a core platform service that has more than 45 million monthly active end users established or located in the Union and more than 10,000 yearly active business users established in the Union in the last financial year; for the purpose of the first subparagraph, monthly active end users shall refer to the average number of monthly active end users throughout the largest part of the last financial year; (c) the requirement in paragraph 1 point (c) where the thresholds in point (b) were met in each of the last three financial years'. 
meeting the thresholds, the core platform service in question fails to meet the abovementioned three-criteria test.

The secondary mechanism is applicable where the thresholds are not met. Pursuant to Article 3(6), the Commission is empowered to designate a provider of core platform services as gatekeeper following a market investigation conducted in accordance with Article 15. ${ }^{20}$ The assessment in question takes a number of 'elements' into consideration, such as the size of the provider, the number of business and end-users depending on access to the platform, the entry barriers or other structural factors. ${ }^{21}$ The Commission shall endeavour to conclude the investigation for the designation of an undertaking as a gatekeeper within 12 months. ${ }^{22}$ The preliminary findings, in turn, are to be submitted within 6 months. ${ }^{23}$ The market investigation can lead to the conclusion that a gatekeeper 'does not yet enjoy an entrenched and durable position in its operations' but that it is 'foreseeable' that it will do so. ${ }^{24}$

\section{B. Operation of the regime}

In accordance with Article 3(7), the Commission is required to identify the undertaking to which the gatekeeper belongs and to list the core platform services that would be subject to obligations insofar as they 'serve as an important gateway' within the meaning of Article $3(1)(b) .{ }^{25}$ As a matter of principle, the regulatory duties laid down in Articles 5 and 6 apply in full to each of the core platform services identified in Article 3(7). These obligations are adjusted, however, where the provider is not found to 'enjoy an entrenched and durable position in its operations' at the time of the assessment but it is 'foreseeable' that it will do so. In such circumstances, and

20 In accordance with Article 15(1), '[t]he Commission may conduct a market investigation for the purpose of examining whether a provider of core platform services should be designated as a gatekeeper pursuant to Article 3(6), or in order to identify core platform services for a gatekeeper pursuant to Article 3(7) [...]'.

21 The elements identified in Article 3(6) are the following:'(a) the size, including turnover and market capitalisation, operations and position of the provider of core platform services; (b) the number of business users depending on the core platform service to reach end users and the number of end users; (c) entry barriers derived from network effects and data driven advantages, in particular in relation to the provider's access to and collection of personal and non-personal data or analytics capabilities; (d) scale and scope effects the provider benefits from, including with regard to data; (e) business user or end user lock-in; (f) other structural market characteristics'

22 Article 15(1).

23 Article 15(2).

24 Article 15(4).

25 In accordance with Article 3(7): 'For each gatekeeper identified pursuant to paragraph 4 or paragraph 6 , the Commission shall identify the relevant undertaking to which it belongs and list the relevant core platform services that are provided within that same undertaking and which individually serve as an important gateway for business users to reach end users as referred to in paragraph $1(\mathrm{~b})^{\prime}$. in accordance with Article 15(4), only some of the duties are applicable to the gatekeeper in question. ${ }^{26}$

The obligations defined in Articles 5 and 6 form the substantive core of the regime. Article 5 identifies the duties that do not require any form of specification or implementation instruments. As such, they are imposed without qualification. In effect, these obligations amount to the prohibition of some relatively frequent practices in the online world. For instance, Article 5 provides that gatekeepers shall allow business users to offer their services via third party platforms at 'prices or conditions' that differ from those offered via its own intermediation service. ${ }^{27}$ In this sense, the Draft DMA opts for an outright ban of 'most favoured-nation' clauses. ${ }^{28}$ Other obligations enshrined in Article 5 appear to express a concern with gatekeepers conditioning access to certain services to the provision of ancillary ones. ${ }^{29}$

Article 6 lists a number of obligations that would typically require further specification. The refinement and adjustment of these duties is foreseen due to the transformative potential they have. At least in theory, they provide the means to restructure, in fundamental ways, many activities in the digital sphere. Article 6 empowers the Commission to alter gatekeepers' ecosystems and change the design of products. Such outcomes can be achieved, for instance, by requiring the providers of core platform services to open to competitors some layers that they might have chosen to keep for themselves. In the same vein, intervention under Article 6 may require gatekeepers to alter their business model where their core monetisation strategies are declared to go against the goals of the regime. The provision also empowers the authority to reallocate rents across the value chain. Any such decisions involve careful choices; accordingly, a blanket mandate may lack the necessary precision and may be difficult to administer.

In line with what has been suggested above, the obligations for which Article 6 provides seek to prevent the (i) strengthening, (ii) leveraging and (iii) exploitation

26 Article 15(4) provides that the gatekeeper in question is subject 'only obligations laid down in Article 5(b) and Article 6(1) points (e), (f), (h) and (i) as specified in the designation decision'.

27 Pursuant to Article 5(b), a gatekeeper shall 'allow business users to offer the same products or services to end users through third party online intermediation services at prices or conditions that are different from those offered through the online intermediation services of the gatekeeper'.

28 This position seems to go against the consensus in the economic literature, which suggests that these clauses have an ambivalent effect on competition and should be subject to a case-by-case effects analysis. For an analysis, see Avantika Chowdhury, 'Most favoured nation clauses: in need of an effects-based approach' (2021) 1 Concurrences 20.

29 See in particular Article 5(e), a gatekeeper shall 'refrain from requiring business users to use, offer or interoperate with an identification service of the gatekeeper in the context of services offered by the business users using the core platform services of that gatekeeper' 
of market power by gatekeepers. Some of the duties relate obviously and directly to the first goal. This is so insofar as they seek to inject rivalry within some segments. In particular, Article 6(1)(j) requires the providers of online search engines to give access to its data to competitors on fair, reasonable and non-discriminatory conditions. ${ }^{30}$ In addition, there are obligations mandating data portability. ${ }^{31}$ Other obligations seem driven by the ambition of preserving rivalry in core platform segments by removing some of the advantages that may favour gatekeepers. For instance, Article 6(1)(b) provides that gatekeepers shall allow the uninstallation of software applications. ${ }^{32}$

A substantial fraction of the practices identified in Article 6 can be interpreted as reflecting a concern with the leveraging of market power from the core platform service to adjacent activities. In fact, the provision codifies several of the self-preferencing tactics that have been investigated by competition authorities in the past years. Thus, Article 6(1)(a) requires that gatekeepers refrain from using not publicly available data generated by the core platform service, which is reminiscent of an ongoing investigation against Amazon at the EU level..$^{33}$ In addition, and in the same vein, the provision requires that gatekeepers give 'effective, high-quality, continuous and real-time access' to such data to third parties. ${ }^{34}$ Article 6(1)(d), in turn, relates to self-preferencing in the context of ranking services, which captures a concern addressed by the Commission in Google Shopping. ${ }^{35}$

30 In accordance with Article 6(1)(j), a gatekeeper shall 'provide to any third party providers of online search engines, upon their request, with access on fair, reasonable and non-discriminatory terms to ranking, query, click and view data in relation to free and paid search generated by end users on online search engines of the gatekeeper, subject to anonymisation for the query, click and view data that constitutes personal data'

31 See in particular Article 6(1)(h), which refers to a duty to 'provide effective portability of data generated through the activity of a business user or end user and shall, in particular, provide tools for end users to facilitate the exercise of data portability, in line with Regulation EU $2016 / 679$, including by the provision of continuous and real-time access'.

32 In accordance with Article 6(1)(b), a gatekeeper shall 'allow end users to un-install any pre-installed software applications on its core platform service without prejudice to the possibility for a gatekeeper to restrict such un-installation in relation to software applications that are essential for the functioning of the operating system or of the device and which cannot technically be offered on a standalone basis by third-parties'.

33 In accordance with Article 6(1)(a), a gatekeeper shall 'refrain from using, in competition with business users, any data not publicly available, which is generated through activities by those business users, including by the end users of these business users, of its core platform services or provided by those business users of its core platform services or by the end users of these business users'. See also Commission, 'Antitrust: EC opens formal investigation against Amazon' IP/19/4291 (Brussels, 16 July 2019).

34 Article 6(1)(i).

35 In accordance with Article 6(1)(d), a gatekeeper shall 'refrain from treating more favourably in ranking services and products offered by the gatekeeper itself or by any third party belonging to the same undertaking compared to similar services or products of third party and apply fair and
Some of the obligations seemingly addressing leveraging concerns go beyond past and ongoing competition law investigations, in the sense that they come across as more ambitious forms of market restructuring. These duties seek to maximise the modularity of digital ecosystems and open additional layers of the value chain to competition. For instance, Article 6(1)(c) appears to introduce a general duty to deal on gatekeepers that would benefit software applications and software application stores. The scope of the duty comprises both the installation and 'effective' use of third-party services running on top of the gatekeeper's operating service. A similar obligation is enshrined in Article 6(1)(f). In this case, it extends to the gatekeeper's 'operating system, hardware or software features', and purports to benefit the users and providers of ancillary services (a category that includes payment systems). ${ }^{36}$

Finally, Article 6 reflects a concern with the exploitation of market power and, by the same token, an ambition to redistribute rents across the value chain. This ambition is particularly apparent in Article 6(1)(k), which expressly requires gatekeepers to apply 'fair and non-discriminatory conditions' of access to business users of software application stores. Again, this duty looks like a codification of a competition law investigation. The commissions charged by the operators of software application stores, in particular Apple, have given rise to complaints and have attracted the attention of competition authorities. ${ }^{37}$ In any event, it would seem that redistribution considerations are also present in many of the strategies that aim at restructuring digital markets. The driver of many disputes that may superficially be seen as relating to leveraging can be more rationalised, more convincingly, as attempts to re-allocate rents away from vertically-integrated incumbents to rivals.

According to the Draft DMA, gatekeepers have the burden of defining the way in which they intend to comply with Article 6 . The relevant question, pursuant to Article 7(1), is whether the approach they follow is 'effective in achieving the objective' sought by the obligation they implement. Given the nature of the duties set out in Article 6, it is natural that Article 7(2) provides the

non-discriminatory conditions to such ranking. See also Google Search (Shopping) (Case AT.39740) Commission Decision of 27 June 2017.

36 In accordance with Article 6(1)(f), a gatekeeper shall 'allow business users and providers of ancillary services access to and interoperability with the same operating system, hardware or software features that are available or used in the provision by the gatekeeper of any ancillary services'.

37 See in particular Commission, 'Antitrust: Commission opens investigation into Apple practices regarding Apple Pay' IP/20/1075 (Brussels, 16 June 2020); and Commission, 'Antitrust: Commission opens investigations into Apple's App Store rules' IP/20/1073 (Brussels, 16 June 2020). 
opportunity for the Commission to specify, by means of a decision, how they are to be implemented by gatekeepers. The adoption of such a decision would follow the opening of proceedings in accordance with Article $18 .^{38}$ In addition, the Draft DMA provides for several mechanisms to address non-compliance (and even systematic non-compliance). Such mechanisms could lead to the adoption of a divestiture decision. ${ }^{39}$

Several of the obligations prescribed under Articles 5 and 6 are issue-specific, in the sense that they have a relatively narrow scope of application. This is explained by the fact that, as already mentioned, many of them are drawn from past and ongoing competition law disputes. Unsurprisingly, the Draft DMA foresees, in Article 10, the possibility of expanding the scope of Articles 5 and 6 by adding new obligations. The introduction of new duties would follow a market investigation conducted in accordance with Article 17. The relevant test to evaluate whether such obligations need to be introduced is whether the practice under consideration is unfair or limits the contestability of core platform services. ${ }^{40}$ Article 10(2) defines the criteria in light of which the test would be satisfied. ${ }^{41}$

\section{The Draft DMA against the constraints of EU competition law}

\section{A. How EU competition law constrains administrative action}

Intervention under the $\mathrm{EU}$ competition law system imposes a number of constraints on competition authorities. The common feature of these constraints is that

38 In accordance with Article 7(2): 'Where the Commission finds that the measures that the gatekeeper intends to implement pursuant to paragraph 1 , or has implemented, do not ensure effective compliance with the relevant obligations laid down in Article 6, it may by decision specify the measures that the gatekeeper concerned shall implement. The Commission shall adopt such a decision within 6 months from the opening of proceedings pursuant to Article 18'.

39 See in particular Article 16 ('market investigation into systematic non-compliance'), which empowers the Commission 'any behavioural or structural remedies which are proportionate to the infringement committed and necessary to ensure compliance with this Regulation', and Article 25, which empowers the Commission to adopt a non-compliance decision.

40 In accordance with Article 10(1), the Commission is empowered to adopt delegated acts where it has identified 'new obligations addressing practices that limit the contestability of core platform services or are unfair in the same way as the practices addressed by the obligations laid down in Articles 5 and 6'.

41 See Article 10(2): 'A practice within the meaning of paragraph 1 shall be considered to be unfair or limit the contestability of core platform services where:(a) there is an imbalance of rights and obligations on business users and the gatekeeper is obtaining an advantage from business users that is disproportionate to the service provided by the gatekeeper to business users; or (b) the contestability of markets is weakened as a consequence of such a practice engaged in by gatekeepers.' they demand a case-by-case, context-specific assessment to ascertain whether the conditions for intervention are present. To begin with, it is necessary to assess whether the trigger-a pre-condition for action-is present. Under Article 101 TFEU, a claimant or authority would need to show that there is explicit coordination (typically in the form of an agreement or a concerted practice) between two or more undertakings. ${ }^{42}$ In the context of Article 102 TFEU, the pre-condition for intervention is a finding of a dominant position, which in turn demands the definition of the relevant market and the evaluation of the features of the latter. ${ }^{43}$ By the same token, EU competition law only prohibits the abuse of a dominant position, not dominance as such. ${ }^{44}$

These constraints significantly limit the scope for intervention under EU competition law in digital markets. In particular, one cannot simply assume that a provider of online platform services enjoys a dominant position within the meaning of Article 102 TFEU, and this even when it has a large turnover (or market share), and it is relied upon by a large number of business or endusers. Similarly, the fact that an undertaking controls an ecosystem does not necessarily mean that its activities are part of a separate market. The relevant question, in the two cases, would revolve around the constraints to which the provider of online platform services is subject, which are to be identified in light of the features of the relevant market. In Microsoft/Skype, for instance, the Commission concluded that the new entity would not enjoy a dominant position in the post-merger scenario, and this even though its market share would be above 80 per cent in a segment that displayed network effects. ${ }^{45}$

Second, the EU competition law system constrains the behaviour of authorities in that, prior to intervention, it demands evidence that the practices under consideration have either the object or the effect of restricting competition. The inquiry cannot be conducted in the abstract, or on the basis of assumptions detached from the circumstances of the case. A consistent line of case law makes it clear that the evaluation of the object of practice is a case-specific inquiry that needs to consider, in particular, the relevant economic and legal context. ${ }^{46}$ As a matter of

42 See in this sense Cases C-2/01 P and C-3/01 P Bundesverband der Arzneimittel-Importeure $\mathrm{eV}$ and Commission v Bayer AG, EU:C:2004:2; and Case T-442/08 International Confederation of Societies of Authors and Composers (CISAC) v Commission, EU:T:2013:188.

43 Case 27/76 United Brands Company and United Brands Continentaal BV $v$ Commission, EU:C:1978:22, para 10.

44 Case 6/72 Europemballage Corporation and Continental Can Company Inc. $v$ Commission, EU:C:1973:22, para 26.

45 Microsoft/Skype (Case COMP/M.6281) Commission Decision of 7 October 2011.

46 See in particular Case C-307/18 Generics (UK) Ltd and others $v$ Competition and Markets Authority, EU:C:2020:52; and Case C-228/18 
principle, conduct is prima facie prohibited irrespective of its effects where it serves no plausible purpose other than the restriction of competition. ${ }^{47}$ This is the case, for instance, of pricing below average variable costs. ${ }^{48}$

When ascertaining the object of a practice, the lessons of experience and economic analysis provide particularly valuable insights. ${ }^{49}$ In effect, such lessons act as additional constraints on the competition authority, in the sense that they cannot be ignored or dismissed in the assessment. In this sense, EU competition law appears to be limited by the boundaries defined by the mainstream consensus. For instance, the fact that an activity presents the features of a two-sided platform must be considered by an authority when evaluating whether a practice is restrictive of competition by its very nature. ${ }^{50}$ More generally, the fact that economic analysis leads to the conclusion that conduct is capable of having pro-competitive (or at least ambivalent) effects is in principle sufficient to rule out that it amounts to a 'by object' infringement. ${ }^{51}$

The above constraints suggest that, in digital markets, only rarely will practices be deemed prima facie unlawful irrespective of their effects. As the overview of the Draft DMA above shows, a substantial fraction of the disputes involving providers of core platform services relates to the fact that the latter are vertically-integrated and thus may have the ability and/or the incentive to favour their activities. Decades of expertise and economic analysis reveal that vertical integration is not, in and of itself, contrary to competition on the merits. In fact, it is known to be a source of pro-competitive gains..$^{52}$ There is another factor to consider, which is the absence of experience about the effects of practices in digital markets. This additional factor was acknowledged in the Special Advisers' Report for the Commission and would plead against prima facie prohibitions in online ecosystems. ${ }^{53}$

Where it appears that the object of a practice is not anticompetitive, it can only be prohibited following a

Gazdasági Versenyhivatal v Budapest Bank Nyrt. and Others, EU:C:2020:265.

47 Generics (n 46), para 89; and Budapest Bank (n 46), paras 82-83. For a systematic analysis of the case law, see Pablo Ibáñez Colomo and Alfonso Lamadrid de Pablo, 'On the Notion of Restriction of Competition: What We Know and What We Don't Know We Know' in Damien Gerard, Massimo Merola and Bernd Meyring (eds), The Notion of Restriction of Competition: Revisiting the Foundations of Antitrust Enforcement in Europe (Bruylant 2017).

48 Case C-62/86 AKZO Chemie BV v Commission, EU:C:1991:286, para 71.

49 Budapest Bank (n 46), paras 76-79.

50 Case C-67/13 P Groupement des cartes bancaires $v$ Commission, EU:C:2014:2204, paras 74-75.

51 Budapest Bank (n 46), paras 82-83.

52 This is acknowledged by the Commission in its Guidelines on the assessment of non-horizontal mergers under the Council Regulation on the control of concentrations between undertakings [2008] OJ C265/6.

53 Special Advisers' Report (n 2), 70. case-by-case evaluation of its likely effects. In line with what has already been mentioned, the assessment cannot be purely hypothetical ${ }^{54}$ and must consider the conditions of competition that would have prevailed in the absence of the practice (that is, the relevant counterfactual). ${ }^{55}$ In particular, it would be necessary to show, in light of the economic and legal context, that any anticompetitive effects would be attributable to the practice. ${ }^{56} \mathrm{~A}$ causal link would fail to exist, for instance, where the exclusion of rivals is the consequence of the fact that the goods or services offered by rivals are less attractive in terms of inter alia, 'price, choice, quality or innovation. ${ }^{57}$ Generally speaking, the exclusion of less efficient rivals is a natural consequence of the competitive process and as such beyond reproach from a competition law standpoint. ${ }^{58}$

It has long been clear that anticompetitive effects within the meaning of EU competition law-whether exclusionary or exploitative-amount to more than a competitive disadvantage. For instance, the mere fact that a dominant supplier does not apply the same conditions to all customers is insufficient to trigger the application of Article 102 TFEU. ${ }^{59}$ This aspect of the case law is particularly relevant in digital markets. A significant fraction of the complaints brought against the providers of core platform services relates to the fact that they give a competitive advantage to their affiliates and/or they choose to keep some activities for themselves. As the law stands, for such practices to amount to an abuse, it would be necessary to show, at the very least, that they reduce competitive pressure by limiting rivals' ability and/or incentive to compete.

In some instances, the threshold for intervention in digital markets is higher. There are circumstances in which a practice does not amount to an infringement unless it can be shown that access to an input or platform is indispensable for competition on the adjacent market and that lack of access leads to the elimination of all competition therein. ${ }^{60}$ This line of case law is relevant

54 Case C-23/14 Post Danmark A/S v Konkurrencerådet, EU:C:2015:651, para 65.

55 Budapest Bank (n 46), para 55; and Generics (n 46), paras 112-122. 56 Post Danmark II (n 54), para 47.

57 Case C-209/10 Post Danmark A/S v Konkurrencerådet, EU:C:2012:172, para. 22.

58 Case Case C-413/14 P, Intel Corporation Inc v Commission, EU:C:2017:632, paras 142-143.

59 Post Danmark I (n 57), para 30. See also Case C-295/17 MEO-Serviços de Comunicações e Multimédia SA v Autoridade Tributária e Aduaneira, EU:C:2018:942.

60 See in particular Joined Cases C-241/91 P and C-242/91 P Radio Telefis Eireann (RTE) and Independent Television Publications Ltd (ITP) $v$ Commission, EU:C:1995:98; Case C-7/97 Oscar Bronner GmbH \& Co. KG v Mediaprint Zeitungs- und Zeitschriftenverlag GmbH \& Co. KG and others, EU:C:1998:569; and Case C-418/01 IMS Health GmbH \& Co. OHG v NDC Health GmbH \& Co. KG, EU:C:2004:257. 
whenever intervention would require the dominant firm to 'transfer an asset or enter into agreements with persons with whom it has not chosen to contract.' ${ }^{61}$ Because the indispensability condition is notoriously difficult to meet, it substantially limits the scope for remedial action in digital markets, most obviously where the concern relates to the fact that a core platform provider keeps an activity for itself.

\section{B. The Draft DMA and the constraints that come from competition law}

The Draft DMA dispenses the Commission from the need to engage with the constraints of the competition law system. The legislative proposal relies upon several techniques in this regard. Concerning, to begin with, the pre-conditions for intervention, the Draft DMA defines its scope primarily by reference to a turnover (or capitalisation) and a user threshold. The usual criteria that would inform the question of whether a firm is dominant-including the context-specific evaluation of the features of the relevant market or its position in relation to rivals-are not part of the assessment. The said features (including the extreme returns to scale or the operation of network effects) are not deemed relevant as such. They are presumed to exist and to justify intervention irrespective of the specific circumstances of each market.

It is true that it is open to the provider qualified as a gatekeeper to provide 'sufficiently substantiated arguments' to the effect that it should not be designated as such-and thus should be relieved from regulatory obligations. There are two important factors to consider in this regard, however. First, nothing in the Draft DMA suggests that the Commission would be bound by the case law and administrative practice on dominance. In fact, the degree of rivalry does not seem to play a role in the assessment. Second (and arguably more importantly), the arguments advanced by providers of core platform services would only be considered, if at all, only following a reversal of the burden. Under Article 102 TFEU, it is for the authority or claimant to show, to the requisite legal standard, that a firm is dominant. Under the Draft DMA, conversely, it is for the firm meeting the thresholds to show that it should not be designated as a gatekeeper.

Similarly, the Draft DMA does not make intervention contingent on a finding that the practices described in Articles 5 and 6 have as their object or effect the restriction of competition. What is more, the legislative proposal does not leave any room for gatekeepers to challenge

61 Case C-552/03 P Unilever Bestfoods (Ireland) Ltd v Commission, EU:C:2006:607, para 137. their regulatory duties on grounds that their conduct is incapable or unlikely to have anticompetitive effects. In fact, the Preamble to the Draft DMA makes it explicit that the duties imposed by virtue of Articles 5 and 6 do not depend on their impact on competition in a given market. Thus, the protection of fairness and contestability in relation to core platform services is independent from the protection of the competitive process as understood under Articles 101 and 102 TFEU.

The boundaries of these concepts-fairness and contestability-are not defined in the legislative proposal. In any event, Articles 5 and 6 suggest that, to the extent that they place constraints on the Commission, these constraints would be considerably less stringent than those resulting from the EU competition law system. First, the Draft DMA appears to allow the Commission to challenge substantial market power as such, and not merely the abuse thereof. In other words, some of the concerns identified in Articles 5 and 6 (as well as the Preamble) do not necessarily relate to practices having an anticompetitive object or effect. They may also have to do with the fact that providers of core platform services operate in markets in which entry is difficult to sustain. Obligations imposing a duty to deal on online search engines, for instance, appear to reflect a concern with the entrenched position of providers in a market characterised by extreme returns to scale; it does not seem driven by a concern with a particular line of conduct. The same can be said of obligations seeking to open up various layers of the ecosystems in which providers operate.

Second, even if it remains undefined, the scope of the notion of fairness seems broader than that of anticompetitive object and/or effect. Suffice it to consider, in this regard, the legal treatment of 'most favoured-nation' clauses and self-preferencing in the instrument. From a competition law standpoint, there is nothing inherently anticompetitive, or unfair, in 'most favoured-nation' clauses. Economic analysis suggests, in fact, that such clauses are fair insofar as they allow a provider of core platform services to address a genuine concern with freeriding. Similarly, there would be nothing anticompetitive or inherently unfair, from the perspective of Articles 101 and 102 TFEU, in a firm preserving a competitive advantage for itself and refusing to share it with rivals. If rivals retain their ability and incentive to compete in spite of the advantage, there would be no reason to take action against the integrated firm.

Articles 5 and 6 display a different, expansive, vision of the notion of fairness. This new vision has two elements. First, fairness-as understood in the Draft DMAseeks to neutralise the competitive advantages enjoyed by gatekeepers. Accordingly, a market is deemed fair where 
all firms are placed on a level playing field. For instance, gatekeepers would not be entitled to benefit from the data generated by the activity of its business users. Second, the Draft DMA is crafted to give rivals an edge in regulated markets. For instance, business users can benefit from the data generated by the platform, and third-party search engines from the data generated by rivals subject to the regime. In this sense, fairness appears to be driven by an attempt to rebalance the conditions of competition so that gatekeepers and third parties can compete with similar forces.

\section{How the Draft DMA diverges from the EU telecoms regime}

\section{A. The logic and limits of intervention under the EU telecoms regime}

One of the objectives-arguably, the primary one-of the EU telecoms regime is to achieve effective competition (as understood under Articles 101 and 102 TFEU) in the markets covered by its scope. ${ }^{62}$ The essence of the regulatory framework introduced in the wake of the liberalisation of the industry remains intact to this day. The approach to intervention can be summarised around the following principles. First, the regime is based on the idea that competition is the best and most effective form of regulation. In this sense, it aspires to create the conditions in which telecoms activities would be subject to competition law alone. ${ }^{63}$ Second, the framework is expressly biased against intervention. In other words, regulatory obligations are only imposed insofar as they are necessary for the promotion of effective competition and insofar as competition law, alone, would not be up to the task. Third, the said obligations are only contemplated on markets in which effective competition may not easily emerge or be sustained. In addition, intervention is subject to regular review to ensure that it only comes into play where necessary and proportionate.

The practical implementation of these principles is eloquent about the spirit of the EU telecoms regime and the philosophy underpinning its adoption. Under the default market analysis procedure, national regulatory authorities need to overcome two hurdles before imposing ex ante measures. Generally speaking, agencies need to ponder whether intervention at the wholesale level would be necessary to preserve effective competition on

62 See Article 3(2)(b) of the Electronic Communications Code (n 10).

63 Ibid., Recital 29: 'This Directive aims to progressively reduce ex ante sector-specific rules as competition in the markets develops and, ultimately, to ensure that electronic communications are governed only by competition law'. the retail markets to which they relate. ${ }^{64}$ If a forwardlooking analysis reveals that a given retail market does not necessitate ex ante remedies to remain effectively competitive, regulatory obligations imposed at the wholesale level are removed (where in place). As can be seen, the EU telecoms regime is, first and foremost, concerned with the leveraging of dominant positions from wholesale markets to retail markets. In the same vein, ex ante remedies are imposed only insofar as the anticompetitive foreclosure of the relevant retail market would be all but certain in the absence of intervention. The EU telecoms regime does not rule out altogether the direct regulation of downstream activities, in particular by means of price controls, but it is seen as a second best to the promotion of effective competition. ${ }^{65}$

Wholesale markets in which intervention is contemplated can only be subject to regulatory obligations where they fulfil the so-called three-criteria test set out in Article 67(1) of the Electronic Communications Code. ${ }^{66}$ This is one of the hurdles to be overcome by national regulatory authorities. In accordance with the first cumulative criterion, intervention can only be contemplated on markets that display 'high and non-transitory structural, legal or regulatory barriers to entry'. The second criterion, in turn, provides that intervention can only take place on markets that do 'not tend towards effective competition within the relevant time horizon'. Finally, ex ante remedies are only justified where 'competition law alone' would be 'insufficient to adequately address the identified market failure(s)'.

The identification of the candidate (wholesale) markets in which intervention may be justified is facilitated by the adoption, by the Commission, of a Recommendation. ${ }^{67}$ This instrument identifies the segments that presumptively fulfil the 'three-criteria test.' ${ }^{68}$ National regulatory

64 Commission Recommendation (EU) 2020/2245 of 18 December 2020 on relevant product and service markets within the electronic

communications sector susceptible to ex ante regulation in accordance with Directive (EU) 2018/1972 of the European Parliament and of the Council establishing the European Electronic Communications Code [2020] OJ L 439/23, para 6.

65 Ibid., para 20.

66 In accordance with Article 67(1) of the Electronic Communications Code (n 10): ' [ . . . ] A market may be considered to justify the imposition of regulatory obligations set out in this Directive if all of the following criteria are met:(a) high and non-transitory structural, legal or regulatory barriers to entry are present; (b) there is a market structure which does not tend towards effective competition within the relevant time horizon, having regard to the state of infrastructure-based competition and other sources of competition behind the barriers to entry; (c) competition law alone is insufficient to adequately address the identified market failure(s) [ . . ]'.

67 See above, n 64.

68 Ibid., para 7. The Commission has issued four versions of the Recommendation since the adoption of the first version of the EU telecoms regime in 2002. See Commission Recommendation of 11 February 2003 on relevant product and service markets within the electronic communications sector susceptible to ex ante regulation in 
authorities remain free to conclude, in any event, that the said conditions are not fulfilled in the specific national or sub-national circumstances, and thus deregulate the activity in question. ${ }^{69}$ Conversely, they may provide evidence showing that the three criteria are met in markets other than those mentioned in the Recommendation. ${ }^{70}$ The fact that a market-defined in accordance with competition law purposes ${ }^{71}$-meets the 'three-criteria test' does not justify, in and of itself, intervention. As already pointed out, there is a second hurdle national regulatory authorities would need to overcome.

The administration of ex ante remedies is only deemed justified where the market that is susceptible of regulation is not effectively competitive. A market is effectively competitive where no undertaking, alone or jointly with others, enjoys a position of 'significant market power' ('SMP') within the meaning of Article 63 of the Electronic Communications Code. ${ }^{72}$ The notion of 'significant market power' is expressly defined by reference to the notion of dominant position as interpreted by the Court of Justice (hereinafter, the 'Court' or the 'ECJ') in Hoffmann-La Roche. ${ }^{73}$ Accordingly, following the identification of a market that is susceptible to ex ante regulation, the national regulatory authority must designate the undertaking(s) enjoying an SMP position. ${ }^{74}$ If it appears that no undertaking is-alone or jointly with othersdominant, ex ante remedies are not warranted.

Once an SMP position is established on a market that fulfils the 'three-criteria test', national regulatory authorities shall, in accordance with Article 68 of the Electronic Communications Code, impose ex ante obligations on the designated undertakings. Crucially, the said provision makes it explicit that such remedies must respect the principle of proportionality. Thus, national regulatory authorities are required to select 'the least

accordance with Directive 2002/21/EC of the European Parliament and of the Council on a common regulatory framework for electronic communication networks and services [2003] OJ L114/45; Commission Recommendation of 17 December 2007 on relevant product and service markets within the electronic communications sector susceptible to ex ante regulation in accordance with Directive 2002/21/EC of the European Parliament and of the Council on a common regulatory framework for electronic communications networks and services [2007] OJ L344/65; and Commission Recommendation of 9 October 2014 on relevant product and service markets within the electronic communications sector susceptible to ex ante regulation in accordance with Directive 2002/21/EC of the European Parliament and of the Council on a common regulatory

framework for electronic communications networks and services [2014] OJ L295/79.

69 Article 67(3) of the Electronic Communications Code (n 10).

702020 Recommendation on relevant markets (n 64), para 22.

71 Article 64(3) of the Electronic Communications Code (n 10).

72 Ibid., Article 63(2).

73 Case 85/76 Hoffmann-La Roche \& Co. AG v Commission, EU:C:1979:36, para 38.

74 Article 67(4) of the Electronic Communications Code (n 10). intrusive way of addressing the problems identified in the market analysis. ${ }^{75}$ The ex ante remedies that can be imposed following a finding of SMP are set out in Articles $69-74$ and 76-80. These provisions offer, in essence, a sliding scale of obligations, ranging from the least intrusive-non-discrimination ${ }^{76}$ and accounting separation ${ }^{77}$-to the most intrusive-functional separation $^{78}$ and voluntary separation by a verticallyintegrated undertaking. ${ }^{79}$ The more intrusive options are subject to heightened scrutiny. The functional separation of an undertaking, for instance, may only be imposed on an 'exceptional basis."

\section{B. The Draft DMA and the EU telecoms regime compared}

The above description of the EU telecoms regime shows that the similarities between the two frameworks are, to the extent that they exist, superficial. There are fundamental differences in terms of principle and approach between them. The most apparent point of divergence relates to the objectives pursued by one and the other. Whereas the EU telecoms regime aspires to achieve effective competition (as understood under Articles 101 and 102 TFEU), the Draft DMA seeks to ensure that the markets falling under its scope are fair and contestable. In fact, whether a market is effectively competitive appears to be of no relevance for the application of Articles 5 and 6 of the legislative proposal. An overview of these two provisions suggests that at least some of the markets targeted by the Draft DMA are, in all likelihood, effectively competitive in the absence of intervention. In terms of regulatory philosophy, it would appear that the bias against intervention, which is a trademark feature of the EU telecoms regime, does not permeate the logic of remedial action under the Draft DMA.

Since effective competition is not the goal of intervention under the latter, the relationship of the proposal with Articles 101 and 102 TFEU is a different one. Under the EU telecoms regime, any regulatory obligations are rolled back once a market is found to be effectively competitive. To the extent that this is the case, the coexistence between the two systems is expressly designed to be a temporary one. The Draft DMA, on the other hand, foresees a permanent overlap with competition law. The question of whether intervention is still justified depends on the

\footnotetext{
75 Ibid., Article 68(2).

76 Ibid., Article 70.

77 Ibid., Article 71.

78 Ibid., Article 77.

79 Ibid., Article 78.

80 Ibid, Article 77(1).
} 
three criteria set out in Article 3(1) being fulfilled. In accordance with Article 4, the Commission is to review, at least every 2 years, whether the designation of a provider of core platform services as a gatekeeper is still warranted. However, this approach does not defer to, or rely on, competition law principles.

There are also major differences in the implementation of the objectives. It is true that, superficially, intervention under both the Draft DMA and the EU telecoms regime revolves around three criteria. This said, the purpose and operation of the assessment have little in common. As already explained, the point of the test under the EU telecoms regime is, first and foremost, to identify the wholesale segments that necessitate intervention to prevent anticompetitive foreclosure on vertically-related markets. The aim, in other words, is to define, in light of a market-by-market assessment, the instances in which the leveraging of a dominant position can be safely expected in light of the features of the relevant market and its foreseeable evolution. The dominant position, moreover, is not simply assumed to exist and must be established in accordance with competition law principles.

Anticompetitive foreclosure, however, is not a constraint to intervention or a concern, in and of itself, under the Draft DMA. There is no reason to presume or expect that anticompetitive foreclosure would occur in the absence of intervention under Articles 5 and 6. In fact, experience and economic analysis do not suggest that anticompetitive effects are invariably likely, let alone certain, to occur in markets that are adjacent to core platform segments. The reports mentioned above, which closely scrutinised the features and functioning of digital markets, fall short of making such a claim. In fact, the current conditions of rivalry around core segments suggest that effective competition does not necessitate regulatory intervention. Suffice it to think, in this regard, of the ecosystem around marketplaces and application stores, in which dozens of players operate. As already pointed out, the point of intervention under the Draft DMA seems rather to restructure activities in the digital value chain to conform to a particular vision of fairness.

Similarly, the implementation of the 'three-criteria test' under the EU telecoms regime has more commonalities with the fact-intensive, context-specific inquiry that is typical of competition law than with the Draft DMA. National regulatory authorities under the former are required to define markets in accordance with competition law principles and to evaluate whether they tend towards effective competition in the relevant time horizon. The 'three-criteria test' under the Draft DMA, on the other hand, is cruder. Instead of relying on the functioning of individual markets within the meaning of competition law, Article 3 revolves around indicators such as the turnover (or capitalisation) and the number of users of a platform. For the same reason, undertakings designated as gatekeepers are not necessarily dominant within the meaning of Hoffmann-La Roche.

Another subtle but major difference in the operation of each of the frameworks has to do with the allocation of the regulatory burden. Under the EU telecoms regime, it is for national regulatory authorities to define the relevant markets susceptible of ex ante intervention and to show that an undertaking enjoys an SMP position therein. In addition, they have the burden of identifying the remedies that would address the market failure(s) identified. Under the Draft DMA, on the other hand, regulatory duties rest with undertakings. Thus, it is for the providers of core platform services to notify to the Commission that they satisfy the thresholds defined in Article 3(2). They also bear the burden of providing 'sufficiently substantiated evidence' to reverse the presumption that they fulfil the three criteria. In addition (and perhaps more importantly), it is for gatekeepers-or at least so in principle-to figure out how they intend to comply with the obligations set out in Articles 5 and 6 . The allocation of the burden may have an impact on the dynamics and the relationship between the regulator and the firms.

These dynamics may be reflected, in particular, in the administration of remedies. Under the EU telecoms regime, the Electronic Communications Code expressly provides that the obligations chosen by the national regulatory authority must respect the principle of proportionality and must be the 'least intrusive' way of addressing the problems identified in the context of the market analysis. This approach captures well the underlying philosophy, which is averse to unwarranted intervention. The Draft DMA, by contrast, makes no express reference to the principle of proportionality in Article $7(1)$. The paragraph merely provides that the measures adopted by a gatekeeper 'shall be effective in achieving the objective of the relevant obligation. The principle of proportionality would only come into play once the Commission opens proceedings to specify, by means of a decision, the manner in which the provider of core platform services is to comply with the obligations set out in Article 6.

As a result of this institutional setting, the Commission is not required to check whether the implementation of the regulatory obligations by the gatekeeper is proportionate; it would merely need to ensure that it is effective. The lessons drawn from competition law enforcement suggest that, where the burden is placed on firms to devise remedies, they may be inclined to go beyond what is strictly necessary to avoid the opening proceedings 
against them. This, in fact, is a recurrent theme in EU competition law. In particular, it appears that, when firms propose commitments within the meaning of Article 9 of Regulation $1 / 2003$, the remedies have often exceeded what would have been required to address any concerns. ${ }^{81}$ In fact, the disproportionate nature of the commitments offered invariably arises in litigation concerning the interpretation of the said provision. ${ }^{82}$

In the specific context of the Draft DMA, firms' inclination to avoid proceedings by going beyond what is necessary to implement the obligations may be further exacerbated by the consequences, in practice, of protracted disagreements with the Commission. By design, the regime penalises delays in the implementation of regulatory obligations. More precisely, there are provisions addressing the gatekeeper's failure to comply with, inter alia, its obligations under Article 5 or 6 (whether or not the latter are specified by means of a decision). The Commission may adopt a non-compliance decision in accordance with Article $25 .{ }^{83}$ This decision may be assorted with a fine. ${ }^{84}$ As mentioned above, there is also a specific procedure for 'systematic non-compliance', which may lead to the adoption of structural remedies. ${ }^{85}$

\section{The definition of untested concepts in the Draft DMA}

\section{A. Administrative action and the definition of the scope of the Draft DMA}

Insofar as it departs from the concepts used in EU competition law, the Draft DMA would not be subject to the limits that would logically derive from the case law interpreting Articles 101 and 102 TFEU. The proposed legislation, in other words, is based on the premise that the Commission would not be constrained by the scope of the said two provisions when it seeks to ensure that digital markets remain fair and contestable. Thus, the measures adopted under Articles 3, 5 and 6 are to be assessed exclusively by reference to the concepts introduced in the Draft DMA. By the same token, any disputes would

81 For a close analysis, see Niamh Dunne, 'Commitment Decisions in EU Competition Law' (2014) 10 Journal of Competition Law \& Economics 399.

82 Case C-441/07 P Commission v Alrosa Company Ltd, EU:C:2010:377; and Case C-132/19 P, Groupe Canal + v Commission, EU:C:2020:1007.

83 In accordance with Article 25(1): 'The Commission shall adopt a non-compliance decision in accordance with the advisory procedure referred to in Article 32(4) where it finds that a gatekeeper does not comply with one or more of the following:(a) any of the obligations laid down in Articles 5 or 6; (b) measures specified in a decision adopted pursuant to Article 7(2) [...]'.

84 Article 26.

85 See above, n 39. revolve around the interpretation of the said concepts. Ultimately, the Court could be called upon to rule on whether a provider of core platform services has been adequately categorised as a gatekeeper and whether a given measure is in keeping with the demands of fairness and contestability (or, perhaps whether it goes beyond what is necessary to attain these goals).

It is relatively infrequent to see the Commission build a regime, based on autonomous legal concepts, wholly from scratch. The decision to regulate digital markets around fairness and contestability raises a number of questions. The fundamental one is whether the Draft DMA's core legal concepts are capable of constraining the behaviour of the authority in a meaningful way. This question arises, in particular, in relation to the criteria to categorise some providers as gatekeepers. In accordance with Article 3(1), the Commission would need to assess, inter alia, whether one such provider has a 'significant impact on the market' or whether its activities serve as an 'important gateway'. The literal wording of the provisions suggests that virtually all providers of some importance would fulfil these conditions. The 'elements' identified in Article 3(6) do not contribute to clarify matters in any significant way. Above all, the said elements are an overview of the characteristics of many markets in the digital sphere (including references to returns to scale, network effects and data-driven advantages). More than dispositive, they are descriptive.

As can be seen, the Draft DMA appears to grant substantial leeway to the Commission to define which firms qualify as gatekeepers. What is more, it is not immediately obvious to see how the providers that meet the thresholds defined in Article 3(2) would be able to rebut, on the basis of 'sufficiently substantiated arguments', the presumption that they have that status. After all, the criteria defined in Article 3(1) are sufficiently broad to justify a finding to that effect in virtually any instance in which an undertaking enjoys at least some degree of market power. Because the criteria are expansive and do not depend on the competitive pressure faced by firms, they could justify the categorisation as gatekeeper even when a given player fails to meet the thresholds defined in Article 3(2). The only constraint, in that regard, seems to be a procedural one: when intervening in accordance with Article 3(6), the Commission would have to conduct a market investigation within the meaning of Article 15.

The conclusion regarding the substantial leeway granted to the Commission is the same if one turns the attention to the specification of the obligations set out in Article 6 (which can be expanded by means of a delegated act). As already explained above, any measures adopted by gatekeepers should be 'effective in achieving the objective of the relevant obligation'. However, there are 
no indications in the Draft DMA as to how to evaluate, in concrete terms, compliance with the duties imposed under Article 6. What is more, gatekeepers would bear the burden of implementing effective measures. The overall objectives of the regime-fairness and contestabilityare not particularly helpful in this regard. As suggested above, the concepts of fairness and contestability are not defined by reference to competition law principles, and the criteria that are relied upon under Articles 101 and 102 TFEU-such as the likelihood of anticompetitive effects, or the fact that efficiency gains can be expected to outweigh any losses-do not seem to be of any relevance. As a result, it is not clear that the Commission would be subject to any limits, defined in advance, when designing and specifying obligations.

How an authority makes use of its leeway may be as important, in practice, as the leeway itself. This is the second key question raised by the design of the Draft DMA. It could choose to define the scope of the 'threecriteria test' in a set of Guidelines or may instead proceed to evaluate the fulfilment of the criteria on a case-by-case basis. The first approach would provide some predictability about the boundaries of the regime. This approach would, however, constrain administrative action by the Commission. ${ }^{86}$ The Draft DMA does not specifically provide for the adoption of delegated acts in relation to the interpretation and application of the 'three-criteria test', as it does for other aspects. ${ }^{87}$ If anything, the proposed legislation seems to favour a case-by-case analysis in the context of a market investigation. In turn, Article 15, the legal basis for such investigations, is strictly procedural in nature.

Limiting the constraints on the Commission is likely to transform the nature of the authority's interaction with stakeholders. The greater leeway the authority enjoys under the Draft DMA can be expected to increase firms' incentives to influence regulatory outcomes. By the same token, it might lead to greater pressure on the Commission to take a particular course of action. To begin with, the breadth and vagueness of the concepts used under Articles 3 and 10 would allow firms to make a plausible case that a firm should be subject to regulatory obligations-or the opposite. Similarly, the potentially far-reaching scope of intervention under Articles 5 and

86 Case C-226/11 Expedia Inc v Autorité de la concurrence and Others, EU:C:2012:795.

87 See in particular Article 3(5), which provides that the Commission may 'adopt delegated acts in accordance with Article 37 to specify the methodology for determining whether the quantitative thresholds laid down in paragraph 2 are met, and to regularly adjust it to market and technological developments where necessary'. In addition, delegated acts may be adopted, in accordance with Article 10(1) to 'update the obligations laid down in Articles 5 and 6.
6 and the absence of apparent constraints could be exploited by potential beneficiaries, in the sense that they would have a clear incentive to seek an expansive interpretation of the relevant provision (or its amendment under Article 10 to capture new practices).

\section{B. Judicial review}

In accordance with Article 263 TFEU, the Court shall review the legality of, inter alia, Commission acts 'intended to produce legal effects vis-à-vis third parties'. There is therefore little doubt that the EU courts would have the power to oversee the interpretation of Articles 3,5 and 6 . In particular, the criteria for the categorisation of the providers of core platform services as gatekeepers and the specification of the obligations set out in Article 6 would be subject to judicial review. More interesting than the theoretical possibility of challenging a Commission act, which is not open to question, is whether the design of the Draft DMA makes such review likely, and whether it would allow it to be meaningful. There are a number of institutional and substantive factors to consider in this regard.

From an institutional perspective, firms potentially subject to Articles 5 and 6 might not necessarily have an incentive to seek litigation. As explained above, the Draft DMA is expressly designed to reward cooperation with the Commission and to disincentivise delays and noncompliance by means of fines and structural remedies. In fact, the proposal includes a commitments procedure to bring non-compliance proceedings to an end. ${ }^{88}$ Another key difference with other regimes, from an institutional standpoint, is that the burden of intervention is placed on providers, not on the authority. In this sense, the situation in which a gatekeeper finds itself under the proposal is comparable to that in which an undertaking finds itself following a decision declaring an infringement. Arguably, this combination of features would make judicial review less likely.

From a substantive standpoint, it is for the Court to define the meaning and scope of the legal concepts used in the Regulation. Administrative action is subject to full review in the EU system. ${ }^{89}$ For instance, it would be for the Court to define what is meant by 'significant impact on the internal market' or what amounts to 'an important gateway for business users to reach end users'. This fact, however, does not necessarily ensure, in and of itself, that the judicial review of intervention under the Draft DMA would be effective and meaningful. It is not

88 Article 23.

89 Paul Craig, EU Administrative Law (3rd edn Oxford University Press 2018), Chapter 15. 
immediately obvious to identify the factors on which the EU courts would rely to control administrative action. This is so because the usual constraints around which judicial review would revolve would not be present-or at least not in principle.

The Draft DMA is based on the premise that competition law principles would not limit administrative action under the new regime. A first question is whether judicial review would be meaningful if this premise were to be accepted. One should note, in this regard, that effective review of administrative action is central to the system devised in the EU Treaties..$^{90}$ If legal concepts were defined in a way that the conditions for intervention were always satisfied, the Commission would have, in effect, the discretion to decide when to intervene. By the same token, it would enjoy the power (if not the iure at least de facto) to shape the meaning of legal provisions. The relevant case law suggests that it would not be possible to reconcile such an institutional set-up with the logic and purpose of Article 263 TFEU. ${ }^{91}$ Effective judicial review would be all the more important in the context of a regime, such as the Draft DMA, which could allow the Commission to impose fines that could go up to 10 per cent of a gatekeeper's turnover ${ }^{92}$ or which could lead to a structural divestiture. ${ }^{93}$

If one accepts, against this background, that the system devised in the EU Treaties demands effective judicial review (and thus the definition of meaningful constraints on administrative action), the following question is that of where the said constraints would originate. A central issue, in this regard, is whether the objectives and legal concepts used in the Draft DMA can be defined autonomously from the objectives and concepts underpinning Articles 101 and 102 TFEU. One should note that the internal market, the proper functioning of which the Draft DMA is meant to advance, 'includes a system ensuring that competition is not distorted. ${ }^{94}$ By definition, the legislative proposal would be part of such a system. For the same reason, a question that might emerge in

90 Case C-389/10 KME Germany AG and Others $v$ Commission, EU:C:2011:816, para 119.

91 See in this sense, by analogy, Case T-399/16 CK Telecoms UK Investments Ltd $v$ Commission, EU:T:2020:217, para 174, where the General Court objected to the definition suggested by the Commission on these same grounds 'It follows that the Commission made an error of law and an error of assessment, in recital 326 of the contested decision, in finding that an "important competitive force" does not need to stand out from its competitors in terms of impact on competition, particularly in so far as such a position would allow it to treat as an "important competitive force" any undertaking in an oligopolistic market exerting competitive pressure'. 92 Article 26.

93 See above, n 39.

94 Protocol (No 27) on the internal market and competition [2008] OJ $115 / 309$. practice is whether all the elements of the system should be interpreted in a consistent manner.

\section{Conclusions}

The Draft DMA gives the Commission substantial leeway to define the firms that are subject to intervention and to restructure ecosystems and business models in the digital arena. The substantive and institutional design of the legislative proposal ensures this outcome. From a substantive standpoint, the Draft DMA is crafted so that the legal and economic limits that derive from EU competition law do not constrain administrative action. From an institutional standpoint, the proposal places the burden of intervention on the undertaking subject to the obligations. In this sense, it differs from the EU telecoms regime, which demands authorities to establish the need for intervention and to identify the least intrusive measures to address any concerns. In practice, gatekeepers' position vis-à-vis the Commission under the Draft DMA is similar to the position in which they would be following a finding of an EU competition law infringement.

The flexibility, the minimisation of the legal and economic boundaries and the allocation of the burden of intervention would all allow the Commission to intervene swiftly and effectively in markets that are subject to constant change. This piece considers some of the implications of this choice. A key consequence is that it is not immediately obvious to see whether, and if so how, administrative action can be subject to effective constraints. For the same reason, the nature of the interaction between the Commission and stakeholders would change. Under competition law and the EU telecoms regime, this interaction is essentially technocratic in nature, in the sense that it revolves around the legal, technical and economic limits developed over time. Because the Draft DMA is built on a blank slate, the said interaction would increase firms' incentives to seek the outcomes they favour. By the same token, the Commission might be subject to greater pressure than in other areas of the law that have well-defined constraints reducing the scope for administrative action.

It would be for the Court to define the boundaries of intervention under the Draft DMA. The issue of judicial review raises a number of questions. In the first place, the legislative proposal is designed to incentivise immediate compliance and negotiated outcomes. The allocation of the burden of intervention and the sliding scale of penalties for non-compliance, which could lead to structural remedies, might make litigation less likely than in the context of competition law and the EU telecoms regime. In the second place, it is not a given that judicial 
review would be meaningful. By design, the Draft DMA minimises the constraints placed on the Commission when defining the scope of the regulation and the obligations to which gatekeepers would be subject. One should note, however, that effective judicial review demands that administrative action be subject to clear, discernible limits defined in advance. In the same vein, a final question is whether the interpretation of the legal concepts found in the legislative proposal should be consistent with, or fully autonomous from, the constraints deriving from the EU competition law system (and, more generally, the system of 'undistorted competition' of which it is a part).

https://doi.org/10.1093/jeclap/lpab065 Advance Access Publication 25 August 2021 